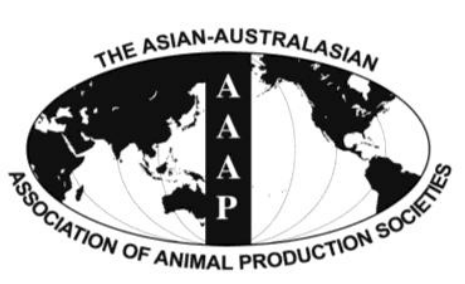

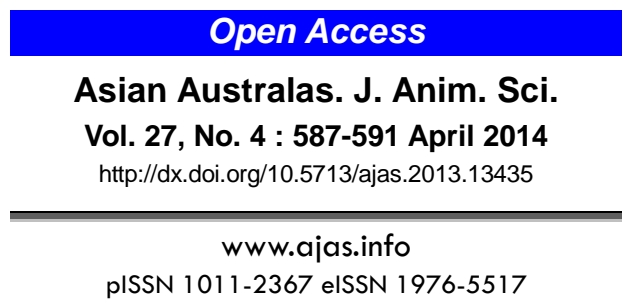

\title{
Differences in Voluntary Cow Traffic between Holstein and Illawarra Breeds of Dairy Cattle in a Pasture-based Automatic Milking System
}

\author{
C. E. F. Clark*, N. B. P. Kwinten ${ }^{1}$, D. A. J. M. van Gastel $^{1}$, K. L. Kerrisk, N. A. Lyons, and S. C. Garcia \\ Dairy Science Group, The University of Sydney, Camden (2570), NSW, Australia
}

\begin{abstract}
Automatic milking systems (AMS) rely upon voluntary cow traffic (the voluntary movement of cattle around a farm) for milk harvesting and feed consumption. Previous research on conventional milking systems has shown differences between dairy cow breeds for intake and milk production, however, the ability to manipulate voluntary cow traffic and milking frequency on AMS farms through breed selection is unknown. This study investigated the effect of breed (Holstein Friesian versus Illawarra) on voluntary cow traffic as determined by gate passes at the Camden AMS research farm dairy facility. Daily data on days in milk, milk yield, gate passes and milking frequency for 158 Holstein Friesian cows and 24 Illawarra cows were collated by month for the 2007 and 2008 years. Illawarra cows had $9 \%$ more gate passes/day than Holstein cows over the duration of the study; however, the milking frequency and milk yield of both breeds were similar. Gate passes were greatest for both breeds in early lactation and in the winter (June to August) and summer (December to February) seasons. These findings highlight an opportunity to translate increased voluntary cow movement associated with breed selection into increased milking frequencies, milk production and overall pasture-based AMS performance. (Key Words: Breed, Voluntary Cow Traffic, Automatic Milking System)
\end{abstract}

\section{INTRODUCTION}

Differences in feed intake and milk production have been reported between breeds of dairy cows offered similar pasture-based diets in conventional milking systems (CMS) (Holmes et al., 1993; L'Hullier et al., 1988; Dillon et al., 2003). Increased hunger and intake per $\mathrm{kg}$ liveweight between breeds have been associated with reduced mature liveweight (Clark et al., 2007) and associated greater surface area of the gastrointestinal tract per kg liveweight (Smith and Baldwin, 1974), and intense genetic selection within breeds such as the Holstein Friesian (Macdonald et al., 2008). As cow appetite is the main motivation for voluntary cow traffic (Prescott, 1998) and voluntary cow traffic is critical to the success of the majority of AMS farms, there is a surprising lack of research on the impact of

\footnotetext{
* Corresponding Author: C. E. F. Clark. Tel: +61-46550712, Fax: +61-246552374, E-mail: cameron.clark@sydney.edu.au

${ }^{1}$ HAS den Bosch University, Hertogenbosch, Netherlands.

Submitted Jul. 18, 2013; Accepted Oct. 28, 2013; Revised Nov. 21, 2013
}

breed on AMS voluntary cow traffic. A breed developed in Australia from Milking Shorthorn, Ayrshire and Devon cattle is the 'Illawarra' occupying $1 \%$ of the national herd in number (ADHIS, 2013). In contrast, the genetics of the Australian Holstein breed have been primarily sourced from overseas and these cattle have been much more intensely selected for milk yield in a different environment. Given the more intense genetic selection for milk yield and associated intake, we tested the hypothesis that appetite and voluntary cow traffic of Holstein Friesian cows would be greater than Illawarra cows in a pasture-based AMS.

\section{MATERIALS AND METHODS}

\section{Research site and animals}

Data was obtained from the Camden AMS research farm, Elizabeth Macarthur Agricultural Institute $\left(34^{\circ} 04^{\prime} \mathrm{S}\right.$; $\left.150^{\circ} 69^{\prime} \mathrm{E}\right)$ from January 2007 to December 2008. The research farm was 41 ha in area. The dairy facility on the AMS research farm comprised a waiting yard, 2 DeLaval 
voluntary milking systems (DeLaval VMS, Tumba, Sweden) and a post-milking feed pad.

Across the two years the herd comprised 36 Illawarra and 206 Holstein Friesian breeds of mixed age which calved year-round. Dry cows and young stock were grazed outside the farm.

\section{Farm system description}

Cows were offered grain-based concentrate in the AMS and other supplements (hay, silage) on the feed pad. Thus, the volume of supplementary feed could be adjusted (at a herd level) to requirement depending on pasture availability.

Cows voluntarily moved around the system, travelling from the pasture to the dairy facility, through the feed pad and back to the pasture with dairy facility access available $24 \mathrm{~h}$ per day. Over the data collection period, cows were offered two areas of pasture across each $24 \mathrm{~h}$ period; the 'day' paddock and 'night' paddock. Cows exiting the dairy between $0900 \mathrm{~h}$ and $2000 \mathrm{~h}$ were drafted to the day paddock where 40 to $50 \%$ of the daily allocation of pasture was offered. Cows remaining in the day paddock at $0700 \mathrm{~h}$ the following day were fetched to the automatic drafting gate at the dairy facility and the total number of cows fetched was recorded. Cows exiting the dairy between $2000 \mathrm{~h}$ and 0900 $\mathrm{h}$ were drafted to the night paddock where 50 to $60 \%$ of the daily allocation of pasture was offered. Cows remaining in the night paddock at $1700 \mathrm{~h}$ the following day were fetched to the dairy facility and the total number of cows fetched was recorded. With this fetching policy in place, all cows passed through the selection gates at the dairy facility at least once per day irrespective of voluntary cow movement. On presentation at the automatic drafting gate, a cow was either directed into the AMS unit if milking permission was granted or to pasture if milking permission was denied. The drafting gates were used to restrict access to the AMS if the time since the cow was last milked was less than $4 \mathrm{~h}$ for cows in early lactation and less than 5 to $6 \mathrm{~h}$ (minimum milking interval) if cows were more than 100 days in milk (DIM).

Water troughs were located in the dairy and on the laneways to ensure that cows had access to water from every pasture allocation.

\section{Measurements and calculations}

Pre- (before cows entered the allocation of pasture) and post- (after the last cow exited the allocation of pasture) grazing compressed pasture height was measured daily by trained staff using a rising plate meter (RPM) $(360 \mathrm{~mm}$ diameter, $315 \mathrm{~g}$ plate weight) fitted with an electronic counter (Farmworks, Palmerston North, New Zealand). Pasture heights were measured in each allocation. These compressed pasture heights were converted to pasture cover as determined for similar pastures and environment (Garcia et al., 2008). Post-grazing pasture cover was then subtracted from pre-grazing cover for the allocated area and divided by the number of cows in the milking herd on that day to calculate the average pasture dry matter intake (DMI) per cow.

Each cow was fitted with an electronic identification transponder. The transponder ensured that the details of all milking and electronic gate passings were electronically recorded by the herd management software (DeLaval VMS Client, Tumba, Sweden). Milk yield at each milking, the time of each gate pass, the number of times a cow was milked per $24 \mathrm{~h}$ period (milking frequency), DIM and parity for each cow were collected.

Each gate passing at the entrance to the dairy facility was defined as a "gate pass" to access a new source of feed. For this study, a cow would pass through this gate at the entrance to the dairy facility if it were to be milked, if it was refused for milking and when required to change from the day to night paddock. Each gate pass was used as a proxy to indicate voluntary cow traffic. Gate passes per cow per day were collated per month (gate passes per month/gate pass days).

The collation of data was as follows:

i) Data recorded in a month that the cow calved or exited the system (culled or dried off) was removed to ensure that there was sufficient data for that month to be representative of overall performance.

ii) Data for a particular cow were removed if there was less than one standard deviation (5.2 months) from the mean (10.9 months) of monthly data to ensure that the overall mean performance for each cow was representative.

iii) Gate passing intervals that were less than $1 \mathrm{~h}$ were removed to account for any cow circulating around the system due to system factors other than motivation.

After this collation, the final data set contained 154 Holstein Friesian cows and 24 Illawarra cows.

As an indication of the genetic merit of the cows remaining in the dataset, the Australian Profit Ranking (APR; the profitability of production and non-production traits relative to the average APR of the Australian dairy herd) was determined for those cows enrolled in herd testing (121 Holstein Friesian and 21 Illawarra cows). The mean APR for Holsteins $(-\$ 50)$ was greater $(\mathrm{p}<0.01)$ than the APR for Illawarra cows (-\$134).

\section{Statistical analysis}

Data were fitted with linear mixed models and parameters were estimated using the restricted maximum likelihood (REML) procedure of GENSTAT for WINDOWS version 14 (Payne et al., 2008). Data were split into categories due to the curvilinear relationship between the fixed effects and response variables analysed. Additionally this provided ease of interpretation of 
outcomes. In this regard, milk yield was split into four quantiles and DIM data split into six quantiles. Parities greater than 5 were grouped. The number (n) of months of cow records in each parity across the two years of data was as follows (parity (n)): 1 (489), 2 (542), 3 (495), 4 (341), 5 (247) and >5 (417).

The model was as follows:

\section{$\mathrm{Y}=$ Fixed $[$ Breed $\times($ Milk yield+DIM+Parity + Month + Year $)]$ + Random (Cow)}

Where Y was gate passes or milking frequency.

Standard error of the difference (SED) was reported for the comparisons presented.

\section{RESULTS AND DISCUSSION}

In contrast to our hypothesis, Illawarra cows had $9 \%$ more gate passes/day than Holstein cows (mean 2.7 vs 2.4 gate passes respectively; $p=0.02$ ). However, the number of gate passes for both breeds were greatest in earlier lactation (Holstein Friesian; 2.6 gate passes/d and Illawarra; 2.9 gate passes/d; $\mathrm{p}<0.05$ ) with Holstein Friesian gate passes decreasing by $10 \%$ to similar levels as Illawarra cows by the 132 DIM quantile (Figure 1). These findings are in line with the greater appetite and cow traffic of early lactation cows associated with greater levels of milk production (Jago et al., 2006; Gygax and Neuffa, 2007). The plateau of gate passes past 100 DIM was likely influenced by the fetching policy where all cows passed through the selection gates at the dairy facility at least once per day irrespective of voluntary cow movement. Without this minimum cap on gate passes caused by fetching, the early lactation trend in gate passes may have continued through to late lactation.

Gate passes were positively associated with milk

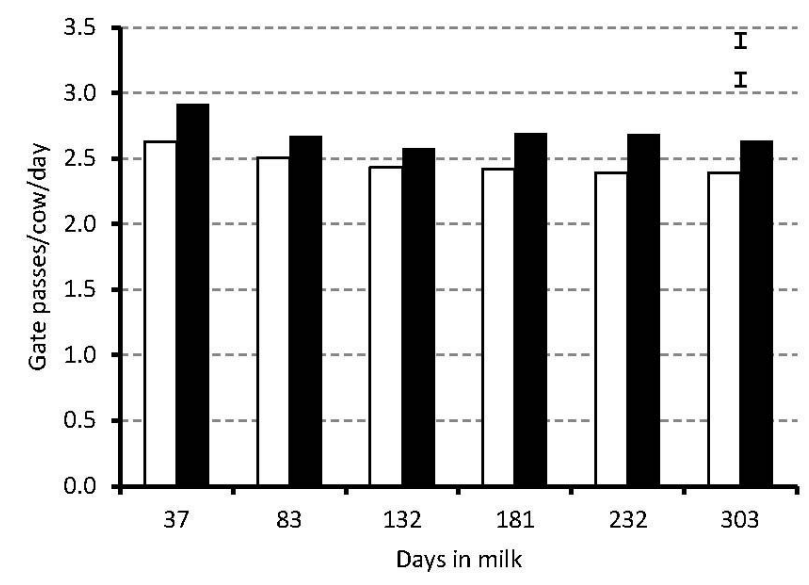

Figure 1. Mean monthly gate passes (per cow per day) for Holstein Friesian (white) and Illawarra (black) cows at each DIM quantile. Top error bar denotes the SED for DIM and lower error bar denotes the SED for breed. production $(\mathrm{p}<0.01)$, with Illawarra cows having greater gate passes than Holstein Friesian cows at the 18.9 and $31 \mathrm{~L}$ milk production quantiles $(\mathrm{p}<0.05)$ (Figure 2$)$. These findings suggest that the Illawarra breed may have a greater feed demand in the pasture-based system evaluated, as compared with Holstein Friesians, at a similar energetic demand. Despite the paucity of research on voluntary cow traffic between breeds in AMS, it is tempting to speculate that the Holstein Friesian cows in the current work mobilised greater body reserves than Illawarra cows to support the energetic requirements of milk production in early lactation. This hypothesis is supported by the tendency of overseas type Holsteins to experience a high degree of negative energy balance in early lactation in pasture-based systems (Clark et al., 2005; Macdonald et al., 2008) and the greatest difference in attempts between breeds occurring at the top quantile $(31 \mathrm{~L})$ of milk production (Figure 2). Alternatively, the Illawarra breed may have a greater tendency to select out more palatable forage than Holstein Friesians to fulfil their energetic requirement which is particularly relevant in pasture-based systems as the quality of pasture generally decreases down the sward profile. As the change in liveweight and body condition score were not evaluated in this study, further work is required to evaluate the impact of breed on both energy balance within pasture-based AMS systems and associated animal health and welfare implications. Also, the impact of breed on feed preference and selection warrants further investigation.

Both breeds had greater gate passes in the summer (December to February) and winter (June to August) months, however, Illawarra cow gate passes greatly exceeded those of Holstein cows in both the summer and winter whilst the two breeds had similar frequencies of gate passes in spring and autumn. The summer and winter months were associated with reduced levels of pasture

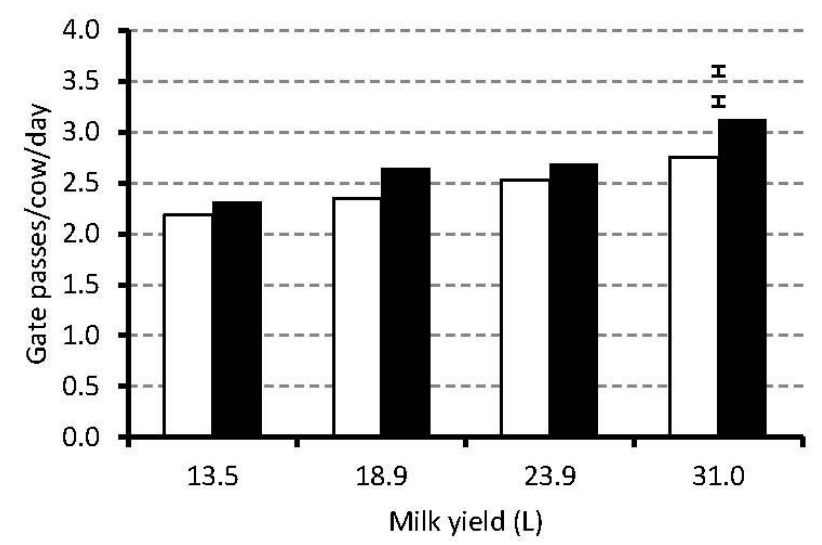

Figure 2. Mean gate passes (per cow per day) for Holstein Friesian (white) and Illawarra (black) cows at each milk yield (L) quantile. Top error bar denotes the SED for milk yield and lower error bar denotes the SED for breed. 
growth at the Camden AMS farm, a lower quantity of pasture offered to avoid overgrazing, and greater amount of supplementary feed offered at the dairy facility (Figure 3). Further work is required to determine potential differences in feeding behaviour between breeds on AMS farms. In this regard, increased gate passes for the Illawarra breed may be due to a greater appetite for supplementary feed and/or a decreased willingness to graze pasture for Illawarra as compared with Holstein cows.

Despite differences in gate passes, both breeds had similar mean daily milk yields (mean $22.1 \mathrm{~L} / \mathrm{d}$ ) and milking frequencies (mean 1.9 milkings/d). Thus, despite the greater proportion of gate passes for Illawarra cows, a high proportion of these extra passes occurred during the defined minimum milking interval with cows directed back to pasture rather than to the AMS unit. The opportunity to take advantage of greater gate passes of certain breeds and individual cows by reducing the minimum milking interval, increasing milking frequency and milk production appears to be dependent on feed system. Work conducted by Rius et al. (2011) showed milk yield to increase by $1.6 \mathrm{~kg} / \mathrm{cow} / \mathrm{d}$ for cows milked 3, vs 2 times in early lactation when offered a predominantly pasture-based diet. In contrast, much greater responses to the same increase in milking frequency $(3.5 \mathrm{~kg} / \mathrm{cow} / \mathrm{d})$ have been reported by others (Stockdale, 2006) for cows predominantly offered a total mixed ration. This potential interaction between milking frequency and feed system for milk yield suggests that the optimal minimum milking interval could vary between breeds of varying DIM through the year on AMS farms, particularly for those farms offering varying levels of supplementation.

There was no interaction between breed and parity for gate passes. For both breeds, gate passes tended to decrease with increasing parity. Overall, dairy cows in parity 1 to 5 (mean 2.6 gate passes/d) had greater gate passes $(\mathrm{p}<0.05)$ than cows of greater parity (mean 2.4 gate passes/d). These findings suggest that the ability and willingness of cows to traffic around an AMS farm system decreases with age. There is a paucity of data on locomotion or lameness to relate with this finding for parity greater than 5 presumably due to other culling reasons before this time, however, work by Bicalho et al. (2008) showed a rapid increase in the incidence of lameness from $10.3 \%$ of the herd for parity 1 , to $34 \%$ of the herd for parity 3 or greater cows. In contrast, heifers (parity 1 animals) use selection gates and achieved their first voluntary milking quicker than naïve (to the AMS) multiparous cows (Jago and Kerrisk, 2011). Together with the current work, these findings highlight the decreased willingness and/or ability of cows to move around an AMS farm as parity increases.

\section{CONCLUSIONS}

Illawarra cows had more gate passes than the Holstein Friesian cows in a pasture-based AMS. These findings



Figure 3. Mean monthly gate passes (per cow per day) for Holstein Friesian (white) and Illawarra (black) cows and mean monthly herd pasture (grey line square markers) and supplement (grey line triangle markers) intakes (kg DM/cow/d) are presented. Top error bar denotes the SED for month and lower error bar denotes the SED for breed. 
suggest that the introduction of an Illawarra cow type into a predominantly Holstein breed herd will improve voluntary cow traffic when conditions are similar to those in this study. Despite an improvement in voluntary cow traffic, the milking frequency and milk yield were the same for both of these breeds. The ability to alter the minimum milking interval on AMS farms to increase the milk production of Illawarra cows given differing feeding systems, and the impact that breed selection has on energy balance for cows on an AMS farm requires further investigation.

\section{ACKNOWLEDGEMENTS}

The authors gratefully acknowledge the contribution of the staff from FutureDairy and NSW Department of Primary Industries for the management of the Camden AMS herd. We wish to acknowledge the input and support of Dairy Australia, NSW Department of Primary Industries, DeLaval and the University of Sydney throughout this project.

\section{REFERENCES}

Australian Dairy Herd Improvement Scheme (ADHIS). 2013. National Herd Recording Statistics 2011/12. www.adhis.com.au

Bicalho, R. C., L. D. Warnick, and C. L. Guard. 2008. Strategies to analyze milk losses caused by diseases with potential incidence throughout the lactation: a lameness example. J. Dairy Sci. 91:2653-2661.

Clark, C. E. F., D. A. Clark, and W. J. Fulkerson. 2007. Feed conversion efficiency and genotype by environment interaction: matching a cow with high feed conversion efficiency to a low input, pasture-based environment. Proc. $3^{\text {rd }}$ Dairy Sci. Symp. pp.129-135.

Clark, C. E. F., W. J. Fulkerson, K. S. Nandra, I. Barchia, and K. L. Macmillan. 2005. The use of indicators to assess the degree of mobilisation of body reserves in dairy cows in early lactation on a pasture-based diet. Livest. Prod. Sci. 94:199-211.

Dillon, P., F. Buckley, P. O'Connor, D. Hegarty, and M. Rath. 2003. A comparison of different dairy cow breeds on a seasonal grass based system of milk production.1. Milk production, live weight, body condition score and DM intake. Livest. Prod. Sci. 83:21-33.

Garcia, S. C., W. J. Fulkerson, and S. U. Brookes. 2008. Dry matter production, nutritive value and efficiency of nutrient utilization of a complementary forage rotation compared to a grass system. Grass Forage Sci. 63:284-300.
Gygax, L., I. Neuffer, C. Kaufmann, R. Hauser, and B. Wechsler. 2007. Comparison of functional aspect in two automatic milking systems and auto tandem milking parlors. J. Dairy Sci. 90:4265-4274.

Holmes, C. W., G. F. Wilson, W. Kuperus, S. Buvaneshwa, and B. Wickham. 1993. Liveweight, feed intake and feed conversion efficiency of lactating dairy cows. Proc. New Zealand Soc. Anim. Prod. 53:95-99.

Jago, J., P. Copeman, K. Bright, D. McLean, I. Ohnstad, and M. Woolford. 2002. An innovative farm system combining automated milking with grazing. Proc. New Zealand Soc. Anim. Prod. 62:115-119.

Jago, J., K. L. Davis, R. Wieliczko, and M. M. Woolford. 2006. The effect of stage of lactation on cow movement in a pasturebased automatic milking system. Proc. New Zealand Soc. Anim. Prod. 66:258-262.

Jago, J. and K. Kerrisk. 2011. Training methods for introducing cows to a pasture-based automatic milking system. Appl. Anim. Behav. Sci. 131:79-85.

L'Huillier, P. J., C. R. Parr, and A. M. Bryant. 1988. Comparative performance and energy metabolism of Jerseys and Friesians in early-mid lactation. Proc. New Zealand Soc. Anim. Prod. 48:231-235.

Macdonald, K. A., G. A. Verkerk, B. S. Thorrold, J. E. Pryce, J. W. Penno, L. R. McNaughton, L. J. Burton, J. A. S. Lancaster, J. H. Williamson, and C. W. Holmes. 2008. A comparison of three strains of holstein-friesian grazed on pasture and managed under different feed allowances. J. Dairy Sci. 91:1693-1707.

Payne, R. W., S. A. Harding, D. A. Murray, D. M. Soutar, D. B. Baird, A. I. Glaser, I. C. Channing, S. J. Welham, A. R. Gilmour, R. Thompson, and R. Webster. 2008. GenStat Release 11 Reference Manual, Part 2 Directives.VSN International, Hemel Hempstead, UK.

Prescott, N. B., T. T. Mottram, and A. J. F. Webster. 1998. Relative motivations of dairy cows to be milked or fed in a Y-maze and an automatic milking system. Appl. Anim. Behav. Sci. 57:2333.

Rius, A. R., K. J. Kay, C. V. C. Phyn, S. R. Morgan, and J. R. Roche. 2010. Milking frequency and milk production in pasture-based lactating dairy cows. Proc. 61st Annual Meeting EAAP, Heraklion, Crete Island, Greece. p. 12.

Spörndly, E. and E. Wredle. 2004. Automatic milking and grazing -effects of distance to pasture and level of supplements on milk yield and cow behavior. J. Dairy Sci. 87:1702-1712.

Smith, N. E. and R. L. Baldwin. 1974. Effects of breed pregnancy, and lactation, on weight of organs and tissues in dairy cattle. J. Dairy Sci. 57:1055-1060. 